\title{
The Significance of Abnormal Systolic Blood Pressure Response during Supine Ergometer Exercise and Postexercise in Ischemic Heart Disease, Studied by Exercise Radionuclide Ventriculography
}

\author{
Ryuichi Ajisaka, M.D., Shigeyuki Watanabe, M.D., \\ Takeshi Masuoka, M.D., Takanori Fujita, M.D., \\ Ryuma Matsumoto, M.D., Kaname Iida, M.D., \\ Takeshi Ogawa, M.D., Yasuro Sugrshita, M.D., Iwao Ito, M.D., \\ Tohru Takeda, M.D., Hinako Toyama, Ph.D., \\ Nobuyoshi Isnikawa, M.D., and Masayoshi Akisada, M.D.
}

\section{SUMMARY}

The prognostic value of abnormal postexercise systolic blood pressure (BP) response has not been investigated. Therefore, the significance of abnormal BP response during exercise and postexercise was examined in 169 patients with ischemic heart disease subjected to supine ergometer exercise gated equilibrium radionuclide ventriculography, coronary arteriography, and follow up averaging 3.6 years.

Abnormal BP response during exercise (exertional "hypotension") was defined as 1) a failure of $\mathrm{BP}$ to rise by at least $11 \mathrm{mmHg}$ or 2) an initial rise in $\mathrm{BP}$ but subsequent fall by more than $10 \mathrm{mmHg}$ during exercise. Abnormal BP response during postexercise (postexercise "hypertension ") was defined as an increase of more than $10 \mathrm{mmHg}$ above the peak exercise BP.

Of 169 patients, $51(30 \%)$ had an abnormal BP response. Four types of BP response were identified: exertional "hypotension" (group la, $\mathrm{n}=11$ ), postexercise "hypertension" (group $1 \mathrm{~b}, \mathrm{n}=30$ ), exertional "hypotension" with postexercise "hypertension" (group lc, $\mathrm{n}=10$ ) and normal BP response (group 2, $\mathrm{n}=118$ ). Both average exercise duration and peak heart rate were significantly lower in groups $1 \mathrm{a}, 1 \mathrm{~b}$ and $\mathrm{l} c$ than in group 2. The severity of exercise ST-segment depression was greater in groups $1 \mathrm{~b}$ and $\mathrm{lc}$ than in group 2. However, there was no significant difference in the severity of exercise ST-segment depression between group $l a$ and group 2. $\Lambda$ decline in ejection fraction occurred more frequently in groups $1 b$ and $l c$ than in group 2. $\mathrm{Pa}$ -

From the Cardiovascular Division, Departments of Internal Medicine and Radiology, Institute of Clinical Medicine, University of Tsukuba, Tsukuba, Ibaraki, Japan.

Address for reprints: Ryuichi Ajisaka, M.D., Cardiovascular Division, Department of Internal Medicine, Institute of Clinical Medicine, University of Tsukuba, Tsukuba-shi, Ibaraki-ken 305, Japan.

Received for publication June 4, 1988.

Accepted August 26, 1988. 
tients in groups $1 \mathrm{a}, \mathrm{lb}$ and $\mathrm{lc}$ had more extensive coronary artery disease (CAD) than did patients in group 2. Medically treated patients with an abnormal BP response (groups $1 \mathrm{a}, \mathrm{lb}$ and $1 \mathrm{c}$ ) had a poorer prognosis than did those with a normal BP response (group 2).

These findings suggest that an abnormal BP response during supine exercise is infrequent, but is usually associated with impaired exercise tolerance and severe CAD. An abnormal postexercise $\mathrm{BP}$ response is also infrequent, but is more closely associated with evidence of myocardial ischemia and global left ventricular dysfunction than exertional " hypotension". In conclusion, postexercise "hypertension" has the same value as cxertional "hypotension" as a predictor of poor prognosis.

\section{Additional Indexing Words:}

Left ventricular function Prognosis Postexercise "hypertension"

$\mathrm{I}$

T is well established that an abnormal systolic blood pressure (BP) response during exercise, including exertional hypotension, is strongly associated with severe coronary artery disease (CAD) ${ }^{1}$ ) and an unfavorable prognosis. ${ }^{2-4)}$ In these investigations, exercise was conducted by upright treadmill testing. Although supine ergometer exercise is also frequently used for the evaluation of CAD, the significance of an abnormal $\mathrm{BP}$ response in this procedure has not been studied extensively. ${ }^{5}$ )

Recently, postexercise $\mathrm{BP}$ response was examined by Amon et $\mathrm{al}^{6 /}$ in normal subjects and in patients with CAD to evaluate its diagnostic value and relationship to the severity of the disease. They concluded that the ratios of early recovery BP to the peak exercise BP were more sensitive than exercise electrocardiographic changes and angina for identifying patients with CAD. ${ }^{6}$ Kawakubo et al also reported that an abnormal rise of BP in the recovery phase of a treadmill exercise test was useful as a predictor of severe CAD." However, the relationship between exercise-induced myocardial dysfunction and postexercise BP response has not been studied extensively. The prognostic value of an abnormal postexercise $B P$ response has not been reported.

This study examines the significance of an abnormal BP response during supine ergometer exercise and that of an abnormal postexercise BP response and elucidates their prognostic value.

\section{METHODS}

The patient population was selccted from among 500 consecutive patients undergoing supine ergometer exercise testing at our institution between April, 1982 and September, 1986. Seventy three patients with hypertension were excluded. Ninety four patients with clinical diagnoses of val- 
Table I. Subjects

\begin{tabular}{l|c|c|c}
\hline & N & M/F & Age \\
\hline Effort angina & 41 & $31 / 10$ & $35-77(58 \pm 10)$ \\
with old myocardial infarction & 22 & $18 / 4$ & $37-70(57 \pm 9)$ \\
Old myocardial infarction & 60 & $55 / 5$ & $35-85(54 \pm 10)$ \\
Vasospastic angina & 18 & $15 / 3$ & $35-68(54 \pm 9)$ \\
Chest pain syndrome & 28 & $10 / 18$ & $38-64(52 \pm 7)$ \\
Normal control & 105 & $73 / 32$ & $15-74(42 \pm 14)$
\end{tabular}

vular heart disease, congenital heart disease and cardiomyopathy were also excluded. Furthermore, patients with atrial fibrillation, left bundle branch block, other conduction abnormalities that would preclude evaluating STsegment changes and those receiving digitalis preparations were excluded. The patients with marked bradycardia (less than $50 / \mathrm{min}$ ) or marked tachycardia (more than $150 / \mathrm{min}$ ) and those with aortitis syndrome were also excluded due to the difficulty in measuring their blood pressure. The remaining 274 patients were studied.

Table I presents their clinical profiles. The study group included 169 patients with ischemic heart disease and 105 normal control subjects. All had sinus rhythm and were normotensive. In 105 normal control subjects, cardiac cxamination was normal and no subject had clinical cvidence of cardiomegaly. Although the majority of these subjects had been suspected of having coronary artery disease (CAD), none manifested chest pain or ST-segment depression during exercise testing. Eighty two of the 169 patients with ischemic heart disease had had a myocardial infarction at least 6 months before the study. Twenty two patients with old myocardial infarction and 41 other patients had experienced exertional angina pectoris. All 63 patients had stable angina pectoris that could be reproduced during exercise testing. Eighteen patients with vasospastic angina were diagnosed by the following criteria: (1) Transient ST-segment elevation of more than $0.2 \mathrm{mV}$ from baseline $\mathrm{EGG}$ documented during chest pain occurring at rest; (2) both the chest pain and ST-segment elevation were promptly relieved by sublingual nitroglycerin without any changes in cardiac enzymes; (3) coronary vasospasm was demonstrated by coronary angiography during spontaneous angina or angina provoked by ergonovine maleate. Twenty cight paticnts with chest pain syndrome were included in this study population. All had typical angina pectoris relieved by rest and nitroglycerin, a positive exercise test response (ST-segment depression of more than $0.1 \mathrm{mV}$ in at least one lead), no evidence of coronary artery spasm and angiographically normal epicardial coronary arteries. For 2 days prior to the com- 
mencement of the test, almost all patients were on no medications except sublingual nitrates. However, in a few patients with severe CAD, cardiac medications were not discontinued.

Exercise stress testing was performed by an electrically-braked bicycle ergometer $\left(\right.$ Siemens ${ }^{R}$ ) in the supine position. Exercise was begun at $0.5-$ $1.0 \mathrm{watt} / \mathrm{kg}$ and increased every $3 \mathrm{~min}$ by $0.5 \mathrm{watt} / \mathrm{kg}$. Reasons for stopping the test included moderate chest pain, dyspnea, severe leg fatigue, serious arrhythmia, marked elcctrocardiographic changes $(0.3 \mathrm{mV}$ or more of downsloping or horizontal ST-segment depression) and marked hypertension (systolic blood pressure of $250 \mathrm{mmHg}$ or greater).

The blood pressure was measured indirectly in the left arm with a cuff sphygmomanometer at rest just before testing, during each minute of exercise and every minute thereafter for 5-10 min by any of 3 skilled physicians. A 12-lead electrocardiogram was recorded every minute during the test. An ischemic response was defined as horizontal or downsloping ST-segment depression of at least $0.1 \mathrm{mV}$ of $0.08 \mathrm{sec}$ duration or greater. If there were resting ST-segment changes present, an additional $0.1 \mathrm{mV}$ of ST-segment depression was required to classify the exercise test as positive.

An abnormal systolic blood pressure (BP) response during exercise (exertional "hypotension") was defined as: 1) a failure of BP to rise by at least $11 \mathrm{mmHg}$ (flat $\mathrm{BP}$ response) or 2) initial rise in BP but subsequent fall by more than $10 \mathrm{mmHg}$ during exercise. An abnormal BP response during postexercise (postexercise "hypertension") was defined as an increase of more than $10 \mathrm{mmHg}$ above the peak exercise BP.

Exercise radionuclide ventriculography was performed by a conventional gated equilibrium technique in 160 subjects (134 patients with ischemic heart disease and 26 normal controls). Red blood cells were labeled in vivo by intravenous administration of $4 \mathrm{mg}$ of stannous pyrophosphate in $5 \mathrm{ml}$ of physiologic saline solution, followed $30 \mathrm{~min}$ later by an injection of $20 \mathrm{mCi}$ of technetium-99 m. The gamma camera with a parallel-hole collimator was positioned in the $30^{\circ}$ left anterior oblique view with a caudal angulation of $15^{\circ}$. Imaging was performed both at rest just before exercise and during the last $3 \mathrm{~min}$ of exercise. Left ventricular ejection fraction (EF) was calculated using multiple regions of interest, with semiautomatic edge detection and computer-determined background areas. Ejection fraction was measured at rest and at peak exercise. Ejection fraction response to exercise was evaluated by $\triangle \mathrm{EF}$ (EF at peak exercise minus $\mathrm{EF}$ at rest).

Of 169 patients with ischemic heart disease, 149 had undergone coronary angiography by Judkins' or Sones' technique within 2 weeks after the exercise test. Selective coronary angiograms were recorded after admin- 
istration of sublingual nitroglycerin in multiple left and right anterior oblique views using caudal and cranial angulation where necessary. Coronary angiograms were evaluated by the authors who had not known the results of the exercise test. A significant coronary lesion was defined as one causing greater than $50 \%$ luminal diameter narrowing of the left main coronary artery or greater than $75 \%$ diameter stenosis of a major epicardial coronary artery.

All 169 patients with ischemic heart disease were followed up annually for 18 to 72 months (mean 43). Of 169 patients, 38 patients who had early (less than 1 year after the exercise test) coronary revascularization (coronary bypass surgery or percutaneous coronary angioplasty) were excluded from the follow up analysis. The adverse cardiac events were defined as cardiac death, non-fatal myocardial infarction and late coronary revascularization (more than 1 year after the test). Only one event was considered in each patient, and any event occurring after the initial one was not considered. The only exception was cardiac death. Deaths were interpreted as having a cardiac or noncardiac cause on the basis of evaluation of data on hospitalization and from a family interview.

\section{Statistical analysis:}

Comparisons of patient groups were evaluated with chi-square analysis, Fisher's $\operatorname{method}^{(8)}$ or the unpaired Student's t-test. Differences were considered significant at probability $\mathrm{p}$ values of less than 0.05. Data presented are mean $\pm \mathrm{SD}$.

\section{RESULTS}

Table II presents the BP results in 105 normal control subjects. The change in $\mathrm{BP}(\triangle \mathrm{BP})$ during exercise in normal control subjects was $40.1 \pm$ $14.5 \mathrm{mmHg}$. Therefore, normal $\mathrm{BP}$ response to exercise was defined as a rise of $\mathrm{BP}$ by at least $11 \mathrm{mmHg}$ (mean -2SD). Of 105 normal control subjects, 6 subjects had BPs in the recovery period that were higher than the peak-exercise BPs. However, the rise of $B P$ was less than $10 \mathrm{mmHg}$ in all 6 subjects.

The effect of age on the BP response was further analyzed (Table II). Both the resting BPs and peak-exercise BPs were higher in the older subjects than in the younger subjects. In all age groups, postexercise BP fell in a linear fashion throughout the recovery period until the BP returned to the preexercise level.

The effect of gender on the BP response was further analyzed (Table II). 
Table II. Systolic Blood Pressures $(\mathrm{mmHg})$ at Rest, During Exercise and After Exercise in 105 Normal Control Subjects

\begin{tabular}{|c|c|c|c|c|c|c|c|c|}
\hline & $N$ & Rest & Peak EX & A I & A 2 & A 3 & A 4 & A 5 \\
\hline \multicolumn{9}{|l|}{ Age (yrs) } \\
\hline$\leq 30$ & (19) & $120 \pm 11$ & $157 \pm 18$ & $145 \pm 16$ & $135 \pm 14$ & $130 \pm 13$ & $127 \pm 12$ & $123 \pm 11$ \\
\hline $31 \leq 40 \leq$ & (29) & $127 \pm 16$ & $167 \pm 19$ & $148 \pm 16$ & $138 \pm 14$ & $134 \pm 15$ & $129 \pm 13$ & $127 \pm 14$ \\
\hline $41 \leq 50 \leq$ & (23) & $122 \pm 11$ & $164 \pm 16$ & $143 \pm 17$ & $134 \pm 15$ & $129 \pm 13$ & $127 \pm 12$ & $125 \pm 12$ \\
\hline $51 \leq 60 \leq$ & (24) & $125 \pm 15$ & $170 \pm 15$ & $147 \pm 16$ & $136 \pm 18$ & $133 \pm 14$ & $129 \pm 13$ & $126 \pm 14$ \\
\hline $\begin{array}{l}61 \leq \\
\text { Sex }\end{array}$ & (10) & $130 \pm 16$ & $166 \pm 23$ & $151 \pm 18$ & $142 \pm 16$ & $136 \pm 17$ & $134 \pm 16$ & $131 \pm 13$ \\
\hline Male & $(73)$ & $123 \pm 13$ & $168 \pm 18$ & $148 \pm 17$ & $138 \pm 14$ & $134 \pm 14$ & $130 \pm 13$ & $126 \pm 14$ \\
\hline Female & $(32)$ & $128 \pm 16$ & $158 \pm 16$ & $144 \pm 16$ & $136 \pm 14$ & $131 \pm 15$ & $128 \pm 13$ & $125 \pm 12$ \\
\hline Total & $(105)$ & $125 \pm 14$ & $165 \pm 14$ & $148 \pm 16$ & $137 \pm 14$ & $133 \pm 14$ & $129 \pm 13$ & $125 \pm 17$ \\
\hline
\end{tabular}

$\mathrm{EX}=$ exercise $; \mathrm{A} 1, \ldots, \mathrm{A} 5=1, \ldots, 5 \mathrm{~min}$ after exercise.

Although peak-exercise $\mathrm{BP}$ was higher in the male subjects than in the female subjects, postexercise $\mathrm{BP}$ fell in a linear fashion throughout the recovery period in both male and female subjects.

Of 169 patients with ischemic heart disease, 51 patients $(30 \%)$ exhibited an abnormal BP response (group 1). The 51 patients were then clasisified into 3 subgroups: 11 patients with exertional "hypotension" (group 1a), 30 patients with postexercise "hypertension" (group 1b) and 10 patients with exertional "hypotension" and postexercise "hypertension" (group 1c). The other 118 patients (group 2) had normal BP responses.

Of the 21 patients with exertional "hypotension" (group $1 \mathrm{a}+1 \mathrm{c}$ ), only 3 patients, comprising $2 \%$ of the total number of patients, had exertional hypotension according to the strict definition, that is, a fall in BP to below the resting level. Of the other 18 patients, 3 had an initial rise in BP but subsequent drop and 15 had a flat BP response.

Table III presents the clinical diagnosis in each group. The incidence of abnormal BP response was significantly higher in patients with effort angina (26 of 41 patients, $63 \%$ ) than in patients with old myocardial infarction (OMI) (11 of 60 patients, $18 \%)(\mathrm{p}<0.01)$. The incidence of prior myocardial infarction in group 1a (exertional "hypotension") was 64\% (7 of 11 patients), compared to $33 \%$ (10 of 30 patients) in group $1 \mathrm{~b}$ (postexercise "hypertension"), but the difference was not statistically significant. Although the incidence of effort angina in group la was $45 \%$ (5 of 11 patients), compared to $67 \%$ (20 of 30 patients) in group $1 \mathrm{~b}$, the difference was also not statistically significant.

Table IV presents mean exercise duration and mean maximal heart 
Table III. Incidence of Abnormal Systolic Blood Pressure Response

\begin{tabular}{|c|c|c|c|c|c|}
\hline & $\mathrm{N}$ & Group 1a & Group $1 \mathrm{lb}$ & Group 1c & Group 2 \\
\hline EA & 41 & 3 & $\begin{array}{l}16 \\
26(63 \%)\end{array}$ & 7 & 15 \\
\hline $\mathrm{EA}+\mathrm{MI}$ & 22 & 2 & $\begin{array}{l}4 \\
8(36 \%)\end{array}$ & 2 & 14 \\
\hline MI & 60 & 5 & $\begin{array}{l}6 \\
11(18 \%)\end{array}$ & 0 & 49 \\
\hline VA & 18 & 0 & $\begin{array}{l}2 \\
2(11 \%)\end{array}$ & 0 & 16 \\
\hline \multirow[t]{2}{*}{ CPS } & 28 & 1 & $\begin{array}{l}2 \\
4(14 \%)\end{array}$ & 1 & 24 \\
\hline & 169 & 11 & $\begin{array}{l}30 \\
51(30 \%)\end{array}$ & 10 & 118 \\
\hline
\end{tabular}

$\mathrm{EA}=$ effort angina $; \mathrm{MI}=$ old myocardial infarction $; \mathrm{VA}=$ vasospastic angina $; \mathrm{CPS}=$ chest pain syndrome.

Table IV. Exercise Duration and Peak Heart Rate in Patients with Normal and Abnormal Blood Pressure Response

\begin{tabular}{|c|c|c|c|}
\hline & $\mathbf{N}$ & Exercise duration (sec) & Peak HR (bpm) \\
\hline \multicolumn{4}{|l|}{ IHD } \\
\hline Group 1a & 11 & $242 \pm 95 * \dagger$ & $107 \pm 13^{*}+$ \\
\hline Group 1b & 30 & $282 \pm 88^{*} \uparrow$ & $113 \pm 17 *$ \\
\hline Group 1c & 10 & $196 \pm 82 * \dagger$ & $103 \pm 21 *+\uparrow$ \\
\hline Group $1(1 a+1 b+1 c)$ & 51 & $258 \pm 93 * \dagger$ & $110 \pm 17 *+$ \\
\hline Group 2 & 118 & $340 \pm 109^{*}$ & $120 \pm 17 * *$ \\
\hline Normal control & 105 & $385 \pm 99$ & $126 \pm 18$ \\
\hline
\end{tabular}

rate in each group of patients and normal control subjects. Average exercise duration was significantly lower in patients with ischemic heart disease than in normal control subjects. The duration of exercise in patients with a normal BP response (group 2) was appreciably longer than that in patients with an abnormal BP response (group 1); the shortcst duration was found in group lc patients. Mean maximal heart rate was significantly different between the 2 groups (groups 1 and 2). The exercise heart rate achieved was significantly lower in group $1 \mathrm{a}$ and group $1 \mathrm{~b}$ than in group 2, however, there was no significant difference in mean maximal heart rate between the normal and postexercise "hypertension" groups (groups 1b and 2).

The mean magnitude of exercise-induced ST-segment depression was 


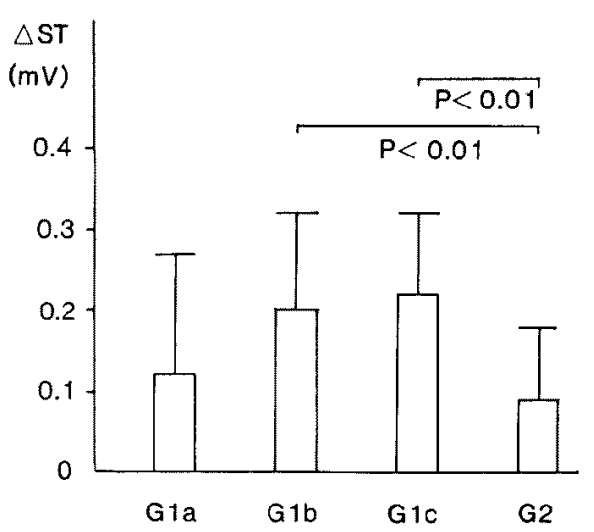

Fig. 1. The mean magnitude of exercise-induced ST-segment depression in each ischemic heart disease group.

Table V. Resting Left Ventricular Ejection Fraction and Its Response to Exercise

\begin{tabular}{l|r|c|c}
\hline & $\mathrm{N}$ & Resting EF (\%) & JEF (\%) \\
\hline IHD & & & \\
Group 1a & 8 & $65 \pm 4$ & $-1 \pm 9 *$ \\
Group 1b & 27 & $61 \pm 15^{* *}$ & $-3 \pm 9 *+\dagger$ \\
Group 1c & 9 & $60 \pm 10^{*}$ & $-7 \pm 9 * \dagger$ \\
Group 1 ( $\mathrm{la}+1 \mathrm{~b}+1 \mathrm{c})$ & 44 & $60 \pm 13^{*}$ & $-4 \pm 9 * \dagger$ \\
Group 2 & 93 & $64 \pm 11^{*}$ & $2 \pm 9 *$ \\
Normal control & 26 & $70 \pm 8$ & $8 \pm 5$ \\
$*$ p<0.01, ** p<0.025 vs Normal control. & & \\
$+\mathrm{p}<0.01, \quad \dagger+\mathrm{p}<0.025$ vs Group 2. & \\
$\mathrm{EF}=\mathrm{ejection}$ fraction.
\end{tabular}

greater in groups $1 \mathrm{~b}$ and $1 \mathrm{c}$ than in group 2 (Fig. 1). The degree of ST segment depression, however, was not significantly different between group $1 \mathrm{a}$ and group 2.

Table $\mathrm{V}$ presents the resting ejection fraction and its response to exercise $(\Delta \mathrm{EF})$ in patients with ischemic heart disease and normal control subjects. Resting EF in patients with ischemic heart disease except for group la was lower than that in normal controls. The difference is probably due to the significant prevalence of old myocardial infarction in patients with ischemic heart disease. However, resting EF did not differ significantly among the 4 subgroups (groups $1 \mathrm{a}, 1 \mathrm{~b}, 1 \mathrm{c}$ and 2).

There was a marked difference in $\Delta \mathrm{EF}$ between patients with ischemic heart disease and normal control subjects (Table V). Among the groups with ischemic heart disease, $\Delta \mathrm{EF}$ in groups $1 \mathrm{~b}$ and $\mathrm{lc}$ was significantly lower 
than that in group 2. However, $\triangle \mathrm{EF}$ was not significantly different between group la and group 2.

Therefore, exercise-induced left ventricular dysfunction in patients with postexercise "hypertension" even in the absence of exertional "hypotension" was more severe than that in patients with a normal BP response. On the other hand, exertional "hypotension" in the absence of postexercise "hypertension" may not always indicate severely impaired left ventricular function during exercise.

The incidence of significant coronary artery stenosis was higher in group $1(1 \mathrm{a}+1 \mathrm{~b}+1 \mathrm{c})(33$ of $39,85 \%)$ than in group $2(64$ of $110,58 \%)$ $(\mathrm{p}<0.01)$. Furthermore, severe coronary artery disease (3-vessel disease or left main trunk stenosis) was also more frequent in group $1(1 \mathrm{a}+1 \mathrm{~b}+1 \mathrm{c})$ $(10$ of $39,26 \%)$ than in group $2(7$ of $110,6 \%)(p<0.01)$.

Among the abnormal BP response groups, the incidence of significant coronary artery stenosis was $83 \%$ (5 of 6 patients) in group 1a, $83 \%$ (20 of 24 patients) in group $1 \mathrm{~b}$ and $89 \%$ ( 8 of 9 patients) in group lc. Although the incidence of severe coronary artery disease in group 1c was $44 \%$ (4 of 9 patients), compared to $33 \%$ (2 of 6 patients) in group la and $17 \%$ (4 of 24 patients) in group $1 \mathrm{~b}$, these differences were not statistically significant $(\mathrm{p}=\mathrm{NS})$.

Patients with postexercise "hypertension" were divided into 2 subgroups according to the duration of postexercise "hypertension", that is, 25 patients with sustained "hypertension" (" hypertension" $>1 \mathrm{~min} ; 1-2$ $(\min ): 5,2-3: 8,3-4: 9,<5: 3)$ and 15 patients with nonsustained "hypertension" ( 1 min or less). The mean exercise duration and the mean maximal heart rate were similar in the 2 groups. However, the incidences of both significant ST-segment depression and abnormal EF response $(\Delta \mathrm{EF}<5 \%)$ were higher in the former group than in the latter group $(\mathrm{p}<0.05, \mathrm{p}<0.05)$. The incidence of significant coronary artery stenosis was also higher in the sustained "hypertension" group than in the nonsustained "hypertension" group $(\mathrm{p}<0.05)$.

Postexercise "hypertension" was also divided by the time when the peak postexercise "hypertension" occurred. Early "hypertension" was defined as the peak "hypertension" occurring within 3 min after exercise, while late "hypertension" as the peak occurring more than 3 min after exercise. The incidence of effort angina was 100\% (14 of 14 patients) in the late "hypertension" group, compared to $62 \%$ (16 of 26 patients) in the early "hypertension" group $(\mathrm{p}<0.05)$. The incidence of significant STsegment depression was also higher in the late "hypertension" group than in the early "hypertension" group $(p<0.05)$. Both groups had a similar 


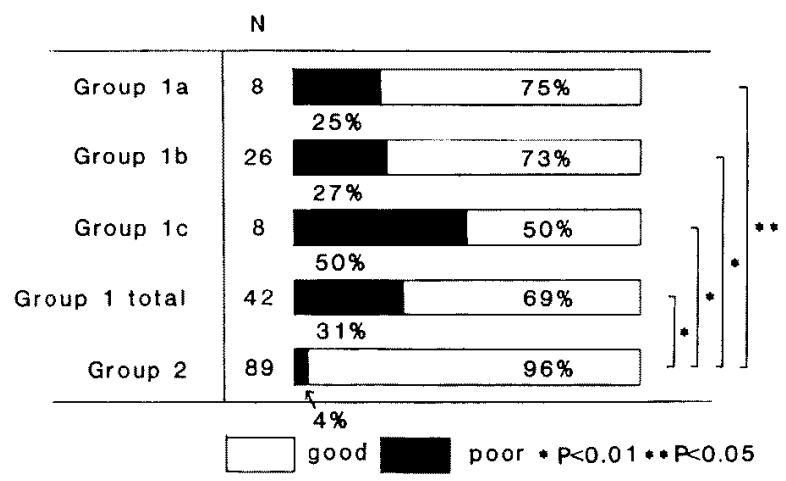

Fig. 2. The incidence of adverse cardiac events in each ischemic heart disease group.

incidence of the other clinical and angiographic variables (exercise duration, maximal heart rate, $\mathrm{EF}$ response and coronary angiographic findings).

Figure 2 presents the incidence of adverse cardiac events in each ischemic heart disease group. There were 13 cardiac events among 42 group 1 patients, for an event rate of $31 \%$; the events were 5 cardiac deaths, 7 myocardial infarctions and 1 late coronary bypass operation. On the other hand, there were only 4 cardiac events among 89 group 2 patients, for an event rate of $4 \%$; the events were 1 cardiac death, 1 myocardial infarction, 1 late coronary bypass operation and 1 late percutaneous coronary angioplasty. When patients with and without an abnormal BP response were compared, there were more events, including death, in the group with an abnormal BP response $(p<0.01)$. When patients of group 2 were compared to patients of groups $1 \mathrm{a}, \mathrm{lb}$ and $1 \mathrm{c}$, there were fewer events in group $2(\mathrm{p}<0.05, \mathrm{p}<$ 0.01 and $\mathrm{p}<0.01$, respectively). Although the incidence of adverse cardiac events was higher in group $1 c$ than in groups $1 \mathrm{a}$ and $1 \mathrm{~b}$, the differences were not statistically significant $(p=N S, N S)$.

\section{Discussion}

Definition of abnormal BP response:

In this study, an abnormal $\mathrm{BP}$ response during exercise was defined as: 1) a failure of $\mathrm{BP}$ to rise by at least $11 \mathrm{mmHg}$ or 2) an initial rise in $\mathrm{BP}$ but subsequent fall by more than $10 \mathrm{mmHg}$ during exercise. This definition seemed to be reasonable because 1) the lower limit (mean - 2SD) of the rise in $\mathrm{BP}$ in normal control subjects was $11 \mathrm{mmHg}$ and 2) the limits of accuracy of the measurement by sphygmomanometer also seemed to be about 
$10 \mathrm{mmHg}$. The definition of abnormal $\mathrm{BP}$ responsc during exercise in this study was almost the same as that of Sanmarco et al.1)

Fraser et al reported that a second significant rise in systolic pressure (detected by a direct method) occurred between 10 and $30 \mathrm{sec}$ after an immediate and significant fall by 6 to $10 \mathrm{mmHg}$ during the first minute of recovery in older healthy subjects. ${ }^{91}$ Ellestad mentioned that in normal subjects systolic blood pressure declined steadily from $1 \mathrm{~min}$ after treadmill testing throughout the recovery period. ${ }^{101}$

Although the exercise method for this study differed from those for the previous studies with respect to patient position during exercise, $6(6 \%)$ of 105 normal subjects had a rise in systolic blood pressure to above the peak systolic blood pressure during exercise at $1 \mathrm{~min}$ after exercise. However, none of the subjects had a rise in postexercise $\mathbf{B P}$ greater than $10 \mathrm{mmHg}$. Therefore, it may be an insignificant change because clinical sphygmomanometry has a limitation in accuracy. Therefore, abnormal BP response during postexercise (from $1 \mathrm{~min}$ after exercise) was defined as an increase of more than $10 \mathrm{mmHg}$ above the peak exercise BP.

\section{Incidence of abnormal BP response:}

The frequency of abnormal blood pressure response varies widely between studies depending on the nature of the study population and the definition of abnormal blood pressure response. The prevalence of strictly defined exertional hypotension in the previous studies ranged from 2.7 to $9.3 \%{ }^{\left.\left.4{ }^{4}, 11\right)-13\right)}$ Although the $2 \%$ frequency observed in this study was less than that obtained in studies using upright treadmill exercise, it was consistent with the $3 \%$ frequency reported by Gibbons et al during supine ergometer exercise. ${ }^{5)}$

The 12\% frequency of exertional "hypotension", which includes not only exertional hypotension but also a flat $\mathrm{BP}$ response and initial rise in $\mathrm{BP}$ with subsequent fall, was also lower than the $24 \%$ frequency reported by Sanmarco et al during upright treadmill exercise, using a similar definition." Gibbons et al suggested that exertional hypotension was infrequent in the supine position because supine excrcise was gencrally associated with a larger ventricular volume and a higher systolic blood pressure than upright exercise. $^{51}$

Kawakubo et al reported that the frequency of postexercise BP rise was $24 \%$ in patients with coronary artery disease. "I If postexercise "hypertension " is defined using their definition (abnormal BP rise for more than $2 \mathrm{~min}$ during the recovery phase), the frequency is $9 \%$ in this study. Therefore, postexercise "hypertension" may also be less frequent in supine exercise 
than in upright exercise.

Of 40 patients with postexercise "hypertension", only 10 patients $(25 \%)$ also had exertional "hypotension". Although Kawakubo et al reported that $13(81 \%)$ of 16 patients with postexercise "hypertension" also had exertional "hypotension", this discrepancy in the results was due mainly to the difference in the definition of postexercise "hypertension". The frequency of exertional "hypotension" accompanying postexercise "hypertension" in this study was increased from 25 to $60 \%$ (9 of 15) using their definition.

\section{Clinical significance of abnormal $B P$ response:}

The exercise tolerance evaluated by exercise duration and maximal heart rate was impaired more severely in patients with exertional " hypotension" than in patients with normal BP response in this study. This observation is consistent with both the study using supine exercise ${ }^{5 /}$ and those using upright exercise. ${ }^{3,41,11), 13\}}$

The exercise tolerance was also impaired more severely in patients with postexercise "hypertension" than in patients with normal BP response. There are little, if any, data available regarding the relationship between exercise tolerance and postexercise $\mathrm{BP}$ response.

The patients with exertional "hypotension" in the absence of postexercise "hypertension" (group la) and the patients with normal BP response had a similar degree of ST-segment depression. There are conflicting reports regarding the relationship between exertional hypotension and exercise-induced ST-segment depression. Levites et al reported that the incidence of positive treadmill tests was significantly higher in the hypotensive group. ${ }^{11)}$ Weiner et al also showed that the severity of the exercise ST-segment abnormalities in patients with exertional hypotension was demonstrated by their greater extent, as well as by the greater number of leads in which the depression occurred compared with findings in patients without a decrease in systolic pressure. ${ }^{13)}$ On the other hand, Morris et $\mathrm{al}^{12)}$ and Hammermeister et $\mathrm{al}^{4)}$ reported that no significant differences were observed between those with and without exertional hypotension in the frequency of ST-segment abnormalities with exercise. Hakki et al also reported that ST-segment depression was not different among the 3 groups (normal, blunted and hypotensive BP responses). ${ }^{14}$

Mean maximal ST-segment depression in patients with postexercise "hypertension", regardless of the BP response during exercise, was greater than that in patients with a normal BP response. This observation is consistent with the results of Kawakubo et al though upright treadmill exercise was 
used in their study. ${ }^{7}$

\section{Relation to left ventricular function:}

Mean resting left ventricular ejection fraction in patients with ischemic heart disease was significantly lower than that in normal control subjects because the former included patients with previous myocardial infarction. However, there was no significant difference in mean resting EF between patients with and without an abnormal BP response. This finding is consistent with the previous studies using treadmill exercise. ${ }^{1,3), 13), 151,163}$ However, Hammermeister et al reported that the mean resting EF was lower in patients with exertional hypotension than in patients without hypotension. ${ }^{4}$ Hakki et al also observed a similar finding. ${ }^{14}$ )

There was no significant difference in resting EF between patients with and without postexercise "hypertension" in the present study. This result was consistent with the result of Kawakubo et al."

The relationship between exertional hypotension and exercise-induced left ventricular dysfunction has not been studied cxtensively. Gibbons et al reported that the frequency of a decrease in ejection fraction during supine exercise was significantly greater in patients with exertional hypotension than in patients with a normal BP response. ${ }^{5}$ Ehsani also showed that the ejection fraction during exercise was significantly lower in patients with exertional hypotension than in patients with a normal BP response. ${ }^{16)}$ This study confirmed these results since all 3 patients with exertional hypotension by strict definition showed a decrease in EF during exercise. However, the patients with exertional "hypotension" in the absence of postexercise "hypertension" (group la) had a small decrease in mean EF, and this change was not different from that in patients with a normal BP response (group 2).

There have not been any reports regarding the relationship between postexercise "hypertension" and exercise-induced left ventricular dysfunction. This study revealed that postexercise "hypertension", regardless of the BP response during exercise, was associated with exercise-induced left ventricular systolic dysfunction.

Relationship between abnormal $B P$ response and coronary artery lesions:

This study showed that exertional "hypotension" was a reliable predictor of coronary artery disease and that the prevalence of severe coronary artery disease (left main trunk stenosis or 3-vessel disease) was significantly higher in patients with exertional "hypotension" than in patients with a normal BP response. Previous studies have shown a strong association of exertional hypotension with multivessel coronary artery disease. ${ }^{3,12}$ ) How- 
ever, Hammermeister et al reported that exertional hypotension was an insensitive indicator of significant left main coronary artery stenosis or 3vessel disease. ${ }^{4)}$

Patients with postexercise "hypertension" also had extensive coronary artery disease. This finding is similar to the data from Kawakubo's rcport in that the frequency of 3-vessel disease was greater in patients with postexercise "hypertension" than in patients with a normal BP response."

\section{Prognostic significance:}

Multiple previous studies have demonstrated that exertional hypotension and/or a flat BP response during upright treadmill exercise is clearly associated with impaired survival. ${ }^{2)-4}$ ) However, the prognostic significance of postexercise " hypertension" has not been reported.

This study demonstrated that both a "hypotensive" response during supine exercise and a "hypertensive" response during postexercise were associated with poor prognosis.

\section{Comparison between exertional "hypotension" and postexercise " hypertension":}

Although it may have been an unexpected result that the coincidence of exertional "hypotension" and postexercise "hypertension" was rather infrequent, the two abnormal BP responses may be ascribed at least in part to different mechanisms. Although the two abnormal BP responses were useful as markers of severe CAD, postexercise "hypertension" was more closely associated with exercise-induced left ventricular systolic dysfunction probably secondary to extensive myocardial ischemia. On the other hand, in the absence of postexercise "hypertension", exertional "hypotension" was not related to severe exercise-induced left ventricular dysfunction. Recently, Mazzotta et al showed that abnormal BP responses (hypotensive and flat responses) during exercise were not always related to the severity of left ventricular dysfunction in some patients with acute myocardial infarction. ${ }^{17)}$

\section{Causes of postexercise "hypertension":}

In patients with coronary artery disease, an increase in BP after upright exercise is likely to be associated with a transient increase in stroke volume because of improvement in myocardial asynergy during the recovery period. ${ }^{18}$ However, Rozanski et al showed that regional wall motion improvement after upright stress was at times not observed after supine stress. ${ }^{18}$ Since radionuclide ventriculographic examination was performed in the first 2 min after exercise in their study, improvement in asynergy which occurred more 
than 2 min after exercise was excluded.

Stein et al reported that during recovery from supine exercise the continuing high level of venous return is dissociated from the decreasing heart rate, resulting in a transient increase in end-diastolic volume. ${ }^{19)}$ Wyatt et al suggested in their experimental study that a primary increase in preload improves cardiac output, but at the expense of aggravated ischemia in the presence of severe coronary stenosis. ${ }^{20}$ ) On the other hand, Nichols et al showed that left ventricular function improves promptly after cessation of transient myocardial ischemia because of a pronounced fall in pulmonary blood volume immediately after cessation of upright exercise. ${ }^{211}$ Therefore, postexercise "hypertension" during the relatively late phase of recovery in this study may be associated with delayed improvement in asynergy because a transient increase in preload after supine exercise may aggravate myocardial ischemia.

Secondly, an increase in BP may be associated with myocardial ischemia itself in some patients. Figueras et al suggested that the increase in blood pressure during myocardial ischemia was due to a reflex mechanism. ${ }^{22)}$ Several experimental studies have substantiated the occurrence of sympathetically mediated vasoconstrictor reflexes stemming from the ischemic myocardium. ${ }^{23)-25)}$

It is, however, beyond our investigation to elucidate the mechanisms of an increase in BP after supine exercise.

Sustained and/or late postexercise " hypertension":

Sustained postexercise "hypertension" and/or late postexercise "hypertension" were associated with more severe exercise-induced myocardial ischemia in this study.

The frequency of late phase (more than $3 \mathrm{~min}$ after exercise) postexercise "hypertension" in this study was greater than that in Kawakubo's study. ${ }^{7}$ This difference is probably explained at least in part by the difference in the methods of exercise testing (supine ergometer vs treadmill) because delayed myocardial ischemia after exercise is thought to be more frequent following supine exercise than upright exercise.

\section{Conclusion}

A hypotensive or flat $\mathrm{BP}$ response during supine exercise is infrequent, but is associated with severe coronary artery disease.

An abnormal increase in BP during recovery from supine exercise is usually associated with exercise-induced left ventricular dysfunction second- 
ary to myocardial ischemia.

Both abnormal BP responses are useful as predictors of poor prognosis.

\section{References}

1. Sanmarco ME, Pontius S, Selvester RH: Abnormal blood pressure response and marked ischemic ST-segment depression as predictors of severe coronary artery disease. Circulation 61: 572,1980

2. Bruce RA, DeRouen TA, Peterson DR, Irving JB, Chinn N, Blake B, Hofer V: Noninvasive predictors of sudden cardiac death in men with coronary heart disease. Predictive value of maximal stress testing. Am J Cardiol 39: 833, 1977

3. Irving JB, Bruce RA, DeRouen TA: Variations in and significance of systolic pressure during maximal exercise (treadmill) testing. Relation to severity of coronary artery disease and cardiac mortality. Am J Cardiol 39: 841, 1977

4. Hammermeister KE, DeRouen TA, Dodge HT, Zia M: Prognostic and predictive value of exertional hypotension in suspected coronary heart disease. Am J Cardiol 51: 1261, 1983

5. Gibbons RJ, Hu DC, Clements IP, Mankin HT, Zinsmeister AR, Brown ML: Anatomic and functional significance of a hypotensive response during supine exercise radionuclide ventriculography. Am J Cardiol 60: 1, 1987

6. Amon KW, Richards KL, Crawford MH: Usefulness of the postexercise response of systolic blood pressure in the diagnosis of coronary artery disease. Circulation 70: 951, 1984

7. Kawakubo K, Murayama M, Sakamoto S, Ono S, Itai T, Kato N, Sugimoto T: Abnormal rise of systolic blood pressure in the recovery phase of exercise stress test-As a predictor of severe coronary artery disease. Shinzo 18: 651, 1986 (in Japanese)

8. Fisher RA: Statistical Methods for Research Workers, 21.02. Oliver and Boyd, Edinburgh, 1952

9. Fraser RS, Chapman GB: Studies on the effect of exercise on cardiovascular function. II. The blood pressure and pulse rate. Circulation 9: 193, 1954

10. Ellestad MH: Stress Testing: Principles and Practice, FA Davis, Philadelphia, p 124, 1980

11. Levites $\mathbf{R}$, Baker $\mathbf{T}$, Anderson GJ: The significance of hypotension developing during treadmill exercise testing. Am Heart J 95: 745, 1978

12. Morris SN, Phillips JF, Jordan JW, McHenry PI. Incidence and significance of decreases in systolic blood pressure during gated treadmill exercise testing. Am J Cardiol 41: 221, 1978

13. Weiner DA, McCabe CH, Cutler SS, Ryan TJ: Decrease in systolic blood pressure during exercise testing: Reproducibility, response to coronary bypass surgery and prognostic significance. Am J Cardiol 49: 1627, 1982

14. Hakki A, Munley BM, Hadjimiltiades S, Meissner MD, Iskandrian AS: Determinants of ahnormal blood pressure response to exercise in coronary artery disease. Am J Cardiol 57: 71,1986

15. Thomson PD, Kelemen MH: Hypotension accompanying the onset of exertional angina. A sign of scvere compromisc of left ventricular blood supply. Circulation 52: 28, 1975

16. Ehsani AA, Austin MB, Biello D: Impaired left ventricular function during exercise in coronary artery disease and exertional hypotension. Cardiology $75: 24,1988$

17. Mazzotta G, Scopinaro G, Falcidieno M, Glaudiani F, Decaro E, Bonow RO, Vecchio C: Significance of abnormal blood pressure response during exercise-induced myocardial dysfunction after recent acute myocardial infarction. Am J Cardiol 59: 1256, 1987

18. Rozanski A, Elkayam U, Berman DS, Diamond GA, Prause J, Swan HJC: Improvement of resting myocardial asynergy with cessation of upright bicycle exercise. Circulation 67: 529,1983 
19. Stein RA, Michielli D, Fox EL, Krasnow N: Continuous ventricular dimensions in man during supine exercise and recovery. An echocardiographic study. Am J Cardiol 41: 655, 1978

20. Wyatt HL, Daluz PL, Waters DD, Swan HJC, Forrester JS: Contrasting influences of alterations in ventricular preload and afterload upon systemic hemodynamics, function, and metabolism of ischemic myocardium. Circulation 55: 318, 1977

21. Nichols AB, Strauss HW, Moore RH, Guiney TE, Cochavi S, Beller GA, Pohost GM: Acute changes in cardiopulmonary blood volume during upright exercise stress testing in patients with coronary artery disease. Circulation 60: 520, 1979

22. Figueras J, Cinca J: Acute arterial hypertension during spontaneous angina in patients with fixed coronary stenosis and exertional angina: An associated rather than a triggering phenomenon. Circulation 64: 60, 1981

23. Staszewska-Barczak J: The reflex stimulation of catecholamine secretion during the acute stage of myocardial infarction in the dog. Clin Sci 41:419, 1971

24. Malliani A, Peterson DF, Bishop VS, Brown AM: Spinal sympathetic cardiac reflexes. Circ Res 30: 158, 1972

25. Hanley $\mathrm{HG}$, Gostin JC, Skinner NS Jr: Differential reflex adjustments in cutaneous and muscle vascular beds during experimental coronary artery occlusion. Am J Cardiol 27: 513, 1971 